\title{
Forward and Reverse Mapping for WEDM Process using Artificial Neural Networks
}

\author{
Somen Dey and Shankar Chakraborty ${ }^{*}$
}

Department of Production Engineering, Jadavpur University, Kolkata - 700032, India

\begin{tabular}{l}
\hline C H R O N I C L E \\
\hline Article history: \\
Received October 29, 2014 \\
Received in revised format: \\
March 28, 2015 \\
Accepted April 24, 2015 \\
Available online \\
April 27 2015 \\
\hline Keywords: \\
WEDM \\
Artificial neural network \\
Feed forward \\
Back propagation \\
Reverse model
\end{tabular}

\section{A B S T R A C T}

\begin{abstract}
Suitable selection of various machining parameters for wire electrical discharge machining (WEDM) process heavily relies on the operator's experience and manufacturer's technologies because of their numerous and diverse operating ranges. Artificial neural networks have been introduced as an effective tool to predict values of responses and input parameters of different machining processes through forward and reverse modeling approaches respectively. This paper mainly focuses on predicting values of some machining responses, like machining rate, surface roughness, dimensional deviation and wire wear ratio using feed forward back propagation artificial neural network based on six WEDM process parameters, such as pulse on time, pulse off time, peak current, spark gap voltage, wire feed and wire tension. The corresponding reverse model is also developed to recommend the optimal settings of WEDM process parameters for achieving the desired responses according to the requirements of the end users. These modeling approaches are quite efficient to predict the values of machining responses as well as process parameter settings with reduced time and effort which otherwise have to be determined experimentally based on trial and error method. The predicted results are found to be in well congruence with the previously obtained experimental observations.
\end{abstract}

\section{Introduction}

Wire electrical discharge machining (WEDM) is a non-traditional material removal process mainly used to cut hard or difficult-to-cut materials, where the application of a mere traditional machining process is not at all convenient. WEDM is a special form of electrical discharge machining process in which the electrode is a continuously moving electrically conductive wire (made of thin copper, brass or tungsten of diameter 0.05-0.3 mm) (Mukherjee et al., 2012). The movement of this wire is numerically controlled to achieve the desired three-dimensional shape and accuracy of the workpiece. The wire is kept in tension using a mechanical device reducing the tendency of producing inaccurate shapes. The mechanism of material removal in WEDM process involves a complex erosion effect by rapid, repetitive and discrete spark discharges between the wire tool and the job immersed in a liquid

\footnotetext{
* Corresponding author.

E-mail address: s_chakraborty00@yahoo.co.in (S. Chakraborty) 
dielectric (kerosene/deionized water) medium. These electrical discharges melt and vaporize minute amounts of work material, which are ejected and flushed away by the dielectric, leaving small craters on the workpiece (Scott et al., 1991; Spedding \& Wang, 1997 ${ }^{\text {a }}$; Spedding \& Wang, 1997º ; Ho et al., 2004). WEDM process offers several special advantages including higher machining rate, better precision and control, higher surface finish, and the capability to machine a wider range of workpiece materials. In general, it is perceived to be an extremely actuate process and there are various reasons behind this perception. In WEDM process, no direct contact takes place between the wire tool (electrode) and the workpiece; as a result, the adverse effects, such as mechanical stresses, chatter and vibration normally present in conventional machining processes are thus eliminated. The wire used as a tool has high mechanical properties and small diameter that can produce very fine, precise and clean cuts (Saha et al., 2008; Shandilya et al., 2013). Apart from tool and die, mold, and metalworking industries, WEDM process is also being widely used to machine a wide variety of miniature and microparts in metals, alloys, sintered materials, cemented carbides, ceramics and silicon. Being a competitive and economical machining process, it can thus fulfill the demanding machining requirements of short product development cycle and high surface finish (Ghodsisyeh et al., 2013).

The accuracy and success of WEDM process mainly depends on a large number of process parameters which influence the machining process significantly (Kumar et al., 2013a; Ugrasen et al., 2014). Thus, it is always suggested to determine the optimal operational settings of various WEDM process parameters for achieving enhanced machining performance. For having those optimal WEDM process parameter settings, the machine operator has to often rely on the manufacturer's handbook or take the help of machining experts. In this paper, an attempt is made to develop an intelligent system to establish the input-output relationship of a WEDM process while utilizing forward and reverse mappings of artificial neural networks (ANNs). In forward mapping, machining rate, surface roughness, dimensional deviation and wire wear ratio values are predicted from a known set of six WEDM process parameters, such as pulse on time, pulse off time, peak current, spark gap voltage, wire feed and wire tension. An attempt is also made to develop the corresponding reverse model to predict the recommended process parameter settings for achieving the desired responses to meet the end user's requirements. In this direction, a back propagation neural network (BPNN)-based approach is applied to develop the related ANN models. The batch mode of training is employed for both the supervised learning networks which requires a large set of training data. This requirement for having a large set of training data is fulfilled by artificially generating the necessary data with the help of simulation based on the real time experimental observations of the earlier researchers. The performance of BPNN is also validated against the past experimental data to show its effectiveness and suitability in advanced machining applications in selecting the settings of the most influential process parameters to achieve the desired responses.

\section{Data mining and artificial neural networks}

Data mining, popularly known as knowledge discovery in databases (KDD), refers to the non-trivial extraction of implicit, previously unknown and potentially useful information from data in databases. While data mining and KDD are frequently treated as synonyms, data mining is actually a part of the knowledge discovery process. Various techniques of data mining have been successfully applied in diverse areas, such as computers and information technology, medical sciences, database management systems and manufacturing sciences for creating intelligent systems for prediction purposes.

On the other hand, an ANN is a mathematical or computational model that is inspired by the structure and/or functional aspects of biological neural networks. A neural network consists of an interconnected group of artificial neurons, and it processes information using a connectionist approach to computation. These are powerful data mining tools for modeling, especially when the underlying data relationship is unknown. The ANNs can identify and learn correlated patterns between input data sets and the corresponding target values. After proper training, the ANNs can be used to predict the outcome of 
new independent input data. A feed forward neural network is a biologically inspired classification algorithm. It consists of a (possibly large) number of simple neuron-like processing units, organized in layers. Every unit in a layer is connected with all the units in the previous layer. These connections are not all equal, each connection may have a different strength or weight. The weights on these connections encode the knowledge of a network. Often the units in a neural network are also called nodes. Data enters at the inputs and passes through the network, layer by layer, until it arrives at the outputs. During normal operation, that is when it acts as a classifier, there is no feedback between layers. This is why it is called as feed forward neural network. Thus, feed forward neural networks are one class of ANNs. Back propagation refers to a common method by which these networks can be trained. Training is the process by which the weight matrix of a neural network is adjusted automatically to produce the desired results. A back propagation network usually learns by examples. This algorithm takes datasets as inputs and tries to learn the hidden pattern from these inputs. It changes or adjusts the network's weights according to the learning capability so that when the training is completed, it can provide the required output for a particular input. Back propagation neural networks are ideal for simple pattern recognition and mapping tasks (Sivanandam, 2003; Samarasinghe, 2006).

\section{ANN-based model development for WEDM process}

Kumar et al. (2013) conducted 54 experiments on a four-axis CNC type WEDM (Electronica Sprintcut 734) setup and investigated the effects of six WEDM process parameters, i.e. pulse on time ( $\left.T_{\text {on }}\right)$, pulse off time ( $\mathrm{T}_{\text {off}}$ ), peak current (Ip), spark gap voltage (SV), wire feed (WF) and wire tension (WT) on four process responses, i.e. machining rate (M/c rate) (in $\mathrm{mm} / \mathrm{min}$ ), surface roughness (Ra) (in $\mu \mathrm{m}$ ), dimensional deviation (Dd) (in $\mu \mathrm{m}$ ) and wire wear ratio (WWR). Each of the six WEDM process parameters was set at three different levels, i.e. $T_{\text {on }}$ at $112 \mu \mathrm{s}, 116 \mu \mathrm{s}$ and $120 \mu \mathrm{s}$; $\mathrm{T}_{\text {off }}$ at $44 \mu \mathrm{s}, 50 \mu \mathrm{s}$

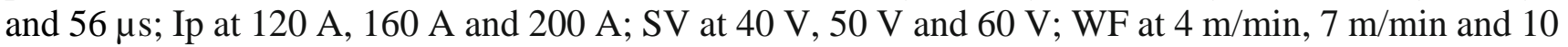
$\mathrm{m} / \mathrm{min}$; and WT at $500 \mathrm{~g}, 950 \mathrm{~g}$ and $1400 \mathrm{~g}$. A work material of pure titanium in the form of a square plate and a brass wire electrode with $0.25 \mathrm{~mm}$ diameter were taken for the experimentation work. The detailed experimental plan along with the observed responses is given in Table 1. The related ANNbased model to predict the responses for a given set of input parameters for the WEDM process is developed in Matlab utilizing the experimental data of Table 1.

Selection of the optimal ANN architecture to be used for prediction is usually decided by hit and trial method, choosing the one which gives the lowest value of mean square error (MSE). The variation of MSE value with changing number of nodes in the hidden layer is exhibited in Fig. 1. Amongst several ANN architectures tried, it is found that the 6-5-4 architecture, as shown in Fig. 2, provides the minimum MSE value. The supervised learning process of an ANN generally requires a large set of training data. In actual practice, this requirement of huge data is fulfilled by generating artificial datasets through simulation. In this case, based on the experimentation data of Table 1, 5000 new datasets are generated for the training purpose. This training data is then linear normalized to achieve better training and prediction results. The details of the developed ANN model for predicting the responses for a given set of WEDM process parameters in forward mapping are given as below.

Number of input nodes - 6 ( $\mathrm{T}_{\text {on }}, \mathrm{T}_{\text {off }}$, Ip, SV, WF, WT)

Number of output nodes - 4 (M/c rate, Ra, Dd, WWR)

Network type - Feed forward back propagation neural network

Training function - TRAINLIM

Adaptation learning function - LEARNGDM

Performance function - MSE

Number of nodes in hidden layer - 5

Transfer function between input and hidden layers - TANSIG

Transfer function between hidden and output layers - PURELIN 


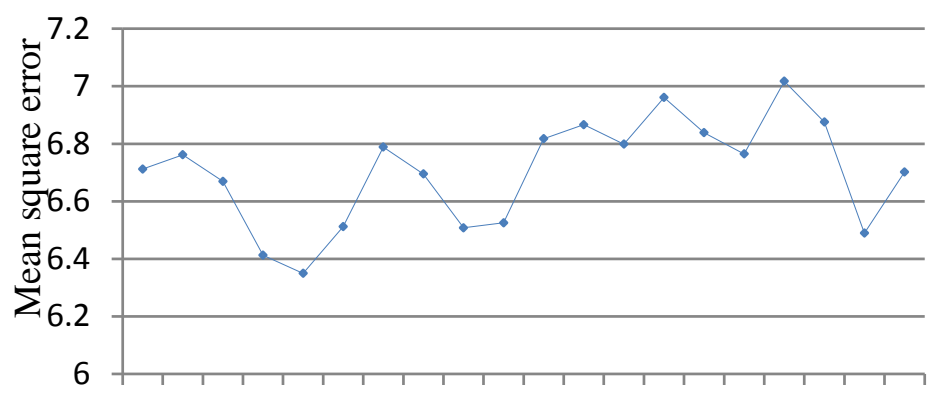

12234456678091011121314151617181920 Number of nodes in hidden layer

Fig. 1. Variation of MSE with changing number of nodes in hidden layer

Table 1

Experimental data for forward mapping (Kumar et al., 2013 ${ }^{\mathrm{a}}$ )

\begin{tabular}{|c|c|c|c|c|c|c|c|c|c|c|}
\hline Exp. No. & $\mathrm{T}_{\text {on }}$ & $T_{\text {off }}$ & Ip & SV & WF & WT & $\mathrm{M} / \mathrm{c}$ rate & $\mathrm{Ra}$ & $\mathrm{D}_{\mathrm{d}}$ & WWR \\
\hline 1 & 120 & 50 & 200 & 50 & 7 & 500 & 1.14 & 3.22 & 160 & 0.095 \\
\hline 2 & 116 & 56 & 160 & 50 & 4 & 500 & 0.576 & 2.48 & 150 & 0.063 \\
\hline 3 & 112 & 50 & 160 & 60 & 4 & 950 & 0.42 & 2.23 & 145 & 0.079 \\
\hline 4 & 116 & 44 & 120 & 50 & 10 & 950 & 0.954 & 2.75 & 159 & 0.086 \\
\hline 5 & 116 & 50 & 120 & 60 & 7 & 500 & 0.544 & 2.47 & 152 & 0.061 \\
\hline 6 & 120 & 50 & 160 & 40 & 4 & 950 & 1.075 & 2.93 & 162 & 0.088 \\
\hline 7 & 116 & 56 & 160 & 50 & 10 & 1400 & 0.586 & 2.48 & 150 & 0.063 \\
\hline 8 & 116 & 50 & 160 & 50 & 7 & 950 & 0.695 & 2.65 & 152 & 0.080 \\
\hline 9 & 116 & 44 & 160 & 50 & 4 & 500 & 1.014 & 2.81 & 160 & 0.089 \\
\hline 10 & 120 & 50 & 160 & 40 & 10 & 950 & 1.075 & 2.94 & 160 & 0.088 \\
\hline 11 & 120 & 56 & 160 & 40 & 7 & 950 & 0.995 & 2.91 & 160 & 0.087 \\
\hline 12 & 120 & 50 & 160 & 60 & 4 & 950 & 0.809 & 2.83 & 159 & 0.079 \\
\hline 13 & 116 & 44 & 160 & 50 & 10 & 500 & 1.012 & 2.79 & 160 & 0.076 \\
\hline 14 & 116 & 50 & 160 & 50 & 7 & 950 & 0.573 & 2.61 & 150 & 0.064 \\
\hline 15 & 112 & 50 & 120 & 50 & 7 & 500 & 0.406 & 2.49 & 145 & 0.048 \\
\hline 16 & 116 & 50 & 160 & 50 & 7 & 950 & 0.697 & 2.68 & 152 & 0.082 \\
\hline 17 & 116 & 50 & 120 & 60 & 7 & 1400 & 0.538 & 2.49 & 150 & 0.059 \\
\hline 18 & 112 & 56 & 160 & 40 & 7 & 950 & 0.48 & 2.32 & 145 & 0.060 \\
\hline 19 & 116 & 56 & 120 & 50 & 10 & 950 & 0.535 & 2.31 & 151 & 0.056 \\
\hline 20 & 116 & 50 & 200 & 40 & 7 & 1400 & 0.825 & 2.89 & 152 & 0.079 \\
\hline 21 & 116 & 50 & 200 & 60 & 7 & 500 & 0.773 & 2.69 & 152 & 0.072 \\
\hline 22 & 116 & 56 & 200 & 50 & 10 & 950 & 0.792 & 2.57 & 153 & 0.074 \\
\hline 23 & 116 & 50 & 120 & 40 & 7 & 1400 & 0.625 & 2.71 & 152 & 0.068 \\
\hline 24 & 112 & 50 & 120 & 50 & 7 & 1400 & 0.425 & 2.51 & 145 & 0.054 \\
\hline 25 & 116 & 56 & 200 & 50 & 4 & 950 & 0.799 & 2.56 & 155 & 0.078 \\
\hline 26 & 120 & 50 & 160 & 60 & 10 & 950 & 0.81 & 2.82 & 153 & 0.081 \\
\hline 27 & 120 & 50 & 120 & 50 & 7 & 500 & 0.83 & 2.77 & 158 & 0.074 \\
\hline 28 & 112 & 50 & 160 & 40 & 10 & 950 & 0.521 & 2.35 & 150 & 0.085 \\
\hline 29 & 112 & 50 & 200 & 50 & 7 & 500 & 0.535 & 2.48 & 150 & 0.083 \\
\hline 30 & 112 & 44 & 160 & 40 & 7 & 950 & 0.858 & 2.70 & 153 & 0.089 \\
\hline 31 & 112 & 50 & 200 & 50 & 7 & 1400 & 0.54 & 2.51 & 150 & 0.082 \\
\hline 32 & 116 & 50 & 160 & 50 & 7 & 950 & 0.658 & 2.65 & 150 & 0.081 \\
\hline 33 & 116 & 44 & 200 & 50 & 4 & 950 & 1.02 & 2.88 & 159 & 0.092 \\
\hline 34 & 116 & 50 & 160 & 50 & 7 & 950 & 0.656 & 2.65 & 152 & 0.081 \\
\hline 35 & 120 & 44 & 160 & 40 & 7 & 950 & 1.28 & 3.28 & 165 & 0.107 \\
\hline 36 & 116 & 44 & 200 & 50 & 10 & 950 & 1.03 & 2.98 & 160 & 0.095 \\
\hline 37 & 116 & 50 & 200 & 40 & 7 & 500 & 0.829 & 2.84 & 155 & 0.079 \\
\hline 38 & 112 & 50 & 160 & 40 & 4 & 950 & 0.529 & 2.33 & 150 & 0.081 \\
\hline 39 & 116 & 56 & 160 & 50 & 10 & 500 & 0.589 & 2.50 & 150 & 0.064 \\
\hline 40 & 116 & 50 & 160 & 50 & 7 & 950 & 0.659 & 2.69 & 152 & 0.081 \\
\hline 41 & 120 & 56 & 160 & 60 & 7 & 950 & 0.792 & 2.66 & 153 & 0.070 \\
\hline 42 & 112 & 44 & 160 & 60 & 7 & 950 & 0.495 & 2.60 & 150 & 0.081 \\
\hline 43 & 116 & 50 & 200 & 60 & 7 & 1400 & 0.778 & 2.68 & 155 & 0.072 \\
\hline 44 & 116 & 44 & 120 & 50 & 4 & 950 & 0.959 & 2.75 & 155 & 0.086 \\
\hline 45 & 112 & 50 & 160 & 60 & 10 & 950 & 0.429 & 2.28 & 145 & 0.079 \\
\hline 46 & 120 & 50 & 120 & 50 & 7 & 1400 & 0.823 & 2.75 & 158 & 0.074 \\
\hline 47 & 112 & 56 & 160 & 60 & 7 & 950 & 0.395 & 2.15 & 140 & 0.064 \\
\hline 48 & 116 & 44 & 160 & 50 & 4 & 1400 & 0.981 & 2.85 & 159 & 0.088 \\
\hline 49 & 116 & 50 & 120 & 40 & 7 & 500 & 0.635 & 2.78 & 158 & 0.068 \\
\hline 50 & 120 & 44 & 160 & 60 & 7 & 950 & 1.000 & 3.00 & 159 & 0.085 \\
\hline 51 & 116 & 56 & 120 & 50 & 4 & 950 & 0.541 & 2.29 & 150 & 0.060 \\
\hline 52 & 120 & 50 & 200 & 50 & 7 & 1400 & 1.052 & 3.12 & 159 & 0.091 \\
\hline 53 & 116 & 44 & 160 & 50 & 10 & 1400 & 0.962 & 2.82 & 155 & 0.088 \\
\hline 54 & 116 & 56 & 160 & 50 & 4 & 1400 & 0.592 & 2.49 & 150 & 0.060 \\
\hline
\end{tabular}


After the training phase using the new 5000 datasets, the developed ANN is employed for forward and backward prediction purposes (Chandrashekarappa et al., 2014). Forward mapping deals with predicting the responses/outputs of the WEDM process for known sets of input conditions. It thus fulfils the end user's requirements of achieving the desired responses for varying values of WEDM process parameters. In forward mapping, the end user may also obtain the tentative response values for an unknown set of WEDM process parameters. Table 2 exhibits the experimentally observed and ANN predicted WEDM response values along with the estimated prediction error for the considered WEDM process based on the experimental data of Table 1. In forward mapping, it is also observed that for a new combination of WEDM process parameter settings (not considered in the actual experimental plan) of $\mathrm{T}_{\text {on }}=112 \mu \mathrm{s}, \mathrm{T}_{\text {off }}=50 \mu \mathrm{s}, \mathrm{Ip}=170 \mathrm{~A}, \mathrm{SV}=50 \mathrm{~V}, \mathrm{WF}=7 \mathrm{~m} / \mathrm{min}$ and $\mathrm{WT}=950 \mathrm{~g}$, the responses are predicted as $\mathrm{M} / \mathrm{c}$ rate $=0.565 \mathrm{~mm} / \mathrm{min}, \mathrm{Ra}=2.51 \mu \mathrm{m}, \mathrm{Dd}=150.84 \mu \mathrm{m}$ and $\mathrm{WWR}=0.07$.

Table 2

ANN predicted results and prediction error for forward mapping

\begin{tabular}{|c|c|c|c|c|c|c|c|c|c|c|c|}
\hline \multicolumn{4}{|c|}{ Experimental results } & \multicolumn{4}{|c|}{ ANN predicted results } & \multicolumn{4}{|c|}{ Prediction error (\%) } \\
\hline $\mathrm{M} / \mathrm{c}$ rate & $\mathrm{Ra}$ & $\mathrm{D}_{\mathrm{d}}$ & WWR & $\mathrm{M} / \mathrm{c}$ rate & $\mathrm{Ra}$ & $\mathrm{D}_{\mathrm{d}}$ & WWR & $\mathrm{M} / \mathrm{c}$ rate & $\mathrm{Ra}$ & $\mathrm{D}_{\mathrm{d}}$ & WWR \\
\hline 1.14 & 3.22 & 160 & 0.095 & 1.10 & 3.12 & 161 & 0.092 & 3.51 & 3.11 & 0.63 & 3.16 \\
\hline 0.576 & 2.48 & 150 & 0.063 & 0.59 & 2.45 & 151 & 0.060 & 2.43 & 1.21 & 0.67 & 4.76 \\
\hline 0.42 & 2.23 & 145 & 0.079 & 0.41 & 2.28 & 144 & 0.075 & 2.38 & 2.24 & 0.69 & 5.06 \\
\hline 0.954 & 2.75 & 159 & 0.086 & 0.95 & 2.82 & 157 & 0.083 & 0.42 & 2.55 & 1.26 & 3.49 \\
\hline 0.544 & 2.47 & 152 & 0.061 & 0.55 & 2.50 & 151 & 0.066 & 1.10 & 1.21 & 0.66 & 8.20 \\
\hline 1.075 & 2.93 & 162 & 0.088 & 1.06 & 3.03 & 162 & 0.087 & 1.40 & 3.41 & 0 & 1.14 \\
\hline 0.586 & 2.48 & 150 & 0.063 & 0.60 & 2.49 & 151 & 0.068 & 2.39 & 0.40 & 0.67 & 7.94 \\
\hline 0.695 & 2.65 & 152 & 0.08 & 0.68 & 2.58 & 152 & 0.074 & 2.16 & 2.64 & 0 & 7.50 \\
\hline 1.014 & 2.81 & 160 & 0.089 & 1.00 & 2.90 & 158 & 0.092 & 1.38 & 3.20 & 1.25 & 3.37 \\
\hline 1.075 & 2.94 & 160 & 0.088 & 1.04 & 3.00 & 161 & 0.085 & 3.26 & 2.04 & 0.63 & 3.41 \\
\hline 0.995 & 2.91 & 160 & 0.087 & 0.96 & 2.91 & 160 & 0.080 & 3.52 & 0 & 0 & 8.05 \\
\hline 0.809 & 2.83 & 159 & 0.079 & 0.85 & 2.82 & 156 & 0.077 & 5.07 & 0.35 & 1.89 & 2.53 \\
\hline 1.012 & 2.79 & 160 & 0.076 & 0.97 & 2.87 & 158 & 0.077 & 4.15 & 2.87 & 1.25 & 1.32 \\
\hline 0.573 & 2.61 & 150 & 0.064 & 0.56 & 2.58 & 152 & 0.062 & 2.27 & 1.15 & 1.33 & 3.13 \\
\hline 0.406 & 2.49 & 145 & 0.048 & 0.43 & 2.56 & 147 & 0.052 & 5.91 & 2.81 & 1.38 & 8.33 \\
\hline 0.697 & 2.68 & 152 & 0.082 & 0.68 & 2.58 & 152 & 0.083 & 2.44 & 3.73 & 0 & 1.22 \\
\hline 0.538 & 2.49 & 150 & 0.059 & 0.50 & 2.58 & 151 & 0.058 & 7.06 & 3.61 & 0.67 & 1.69 \\
\hline 0.48 & 2.32 & 145 & 0.06 & 0.43 & 2.36 & 147 & 0.064 & 10.42 & 1.72 & 1.38 & 6.67 \\
\hline 0.535 & 2.31 & 151 & 0.056 & 0.51 & 2.30 & 150 & 0.053 & 4.67 & 0.43 & 0.66 & 5.36 \\
\hline 0.825 & 2.89 & 152 & 0.079 & 0.86 & 2.81 & 155 & 0.087 & 4.24 & 2.77 & 1.97 & 10.13 \\
\hline 0.773 & 2.69 & 152 & 0.072 & 0.80 & 2.83 & 155 & 0.070 & 3.49 & 5.20 & 1.97 & 2.78 \\
\hline 0.792 & 2.57 & 153 & 0.074 & 0.76 & 2.69 & 153 & 0.078 & 4.04 & 4.67 & 0 & 5.41 \\
\hline 0.625 & 2.71 & 152 & 0.068 & 0.65 & 2.67 & 151 & 0.065 & 4.00 & 1.48 & 0.66 & 4.41 \\
\hline 0.425 & 2.51 & 145 & 0.054 & 0.44 & 2.53 & 147 & 0.054 & 3.53 & 0.80 & 1.38 & 0 \\
\hline 0.799 & 2.56 & 155 & 0.078 & 0.76 & 2.71 & 153 & 0.082 & 4.88 & 5.86 & 1.29 & 5.13 \\
\hline 0.81 & 2.82 & 153 & 0.081 & 0.82 & 2.78 & 156 & 0.076 & 1.23 & 1.42 & 1.96 & 6.17 \\
\hline 0.83 & 2.77 & 158 & 0.074 & 0.86 & 2.79 & 158 & 0.073 & 3.61 & 0.72 & 0 & 1.35 \\
\hline 0.521 & 2.35 & 150 & 0.085 & 0.51 & 2.41 & 148 & 0.086 & 2.11 & 2.55 & 1.33 & 1.18 \\
\hline 0.535 & 2.48 & 150 & 0.083 & 0.54 & 2.48 & 149 & 0.079 & 0.93 & 0 & 0.67 & 4.82 \\
\hline 0.858 & 2.7 & 153 & 0.089 & 0.90 & 2.75 & 154 & 0.094 & 4.90 & 1.85 & 0.65 & 5.62 \\
\hline 0.54 & 2.51 & 150 & 0.082 & 0.51 & 2.41 & 146 & 0.077 & 5.56 & 3.98 & 2.67 & 6.10 \\
\hline 0.658 & 2.65 & 150 & 0.081 & 0.68 & 2.58 & 152 & 0.074 & 3.34 & 2.64 & 1.33 & 8.64 \\
\hline 1.02 & 2.88 & 159 & 0.092 & 1.01 & 3.01 & 157 & 0.095 & 0.98 & 4.51 & 1.26 & 3.26 \\
\hline 0.656 & 2.65 & 152 & 0.081 & 0.68 & 2.58 & 152 & 0.074 & 3.66 & 2.64 & 0 & 8.64 \\
\hline 1.28 & 3.28 & 165 & 0.107 & 1.33 & 3.28 & 166 & 0.101 & 3.91 & 0 & 0.61 & 5.61 \\
\hline 1.03 & 2.98 & 160 & 0.095 & 1.01 & 3.01 & 158 & 0.093 & 1.94 & 1.01 & 1.25 & 2.11 \\
\hline 0.829 & 2.84 & 155 & 0.079 & 0.87 & 2.81 & 156 & 0.078 & 4.95 & 1.06 & 0.65 & 1.27 \\
\hline 0.529 & 2.33 & 150 & 0.081 & 0.56 & 2.43 & 149 & 0.075 & 5.86 & 4.29 & 0.67 & 7.41 \\
\hline 0.589 & 2.5 & 150 & 0.064 & 0.60 & 2.47 & 151 & 0.068 & 1.87 & 1.20 & 0.67 & 6.25 \\
\hline 0.659 & 2.69 & 152 & 0.081 & 0.68 & 2.58 & 152 & 0.074 & 3.19 & 4.09 & 0 & 8.64 \\
\hline 0.792 & 2.66 & 153 & 0.07 & 0.79 & 2.74 & 155 & 0.073 & 0.25 & 3.01 & 1.31 & 4.29 \\
\hline 0.495 & 2.6 & 150 & 0.081 & 0.47 & 2.41 & 147 & 0.077 & 5.05 & 7.31 & 2.00 & 4.94 \\
\hline 0.778 & 2.68 & 155 & 0.072 & 0.78 & 2.73 & 154 & 0.076 & 0.26 & 1.87 & 0.65 & 5.56 \\
\hline 0.959 & 2.75 & 155 & 0.086 & 0.94 & 2.78 & 156 & 0.087 & 1.98 & 1.09 & 0.65 & 1.16 \\
\hline 0.429 & 2.28 & 145 & 0.079 & 0.41 & 2.28 & 144 & 0.075 & 4.43 & 0 & 0.69 & 5.06 \\
\hline 0.823 & 2.75 & 158 & 0.074 & 0.82 & 2.75 & 156 & 0.072 & 0.36 & 0 & 1.27 & 2.70 \\
\hline 0.395 & 2.15 & 140 & 0.064 & 0.39 & 2.26 & 144 & 0.069 & 1.27 & 5.12 & 2.86 & 7.81 \\
\hline 0.981 & 2.85 & 159 & 0.088 & 0.98 & 2.90 & 156 & 0.092 & 0.10 & 1.75 & 1.89 & 4.55 \\
\hline 0.635 & 2.78 & 158 & 0.068 & 0.68 & 2.75 & 152 & 0.068 & 7.09 & 1.08 & 3.80 & 0 \\
\hline 1.00 & 3.00 & 159 & 0.085 & 0.99 & 2.97 & 158 & 0.085 & 1.00 & 1.00 & 0.63 & 0 \\
\hline 0.541 & 2.29 & 150 & 0.06 & 0.50 & 2.44 & 149 & 0.059 & 7.58 & 6.55 & 0.67 & 1.67 \\
\hline 1.052 & 3.12 & 159 & 0.091 & 1.05 & 3.07 & 160 & 0.090 & 0.19 & 1.60 & 0.63 & 1.10 \\
\hline 0.962 & 2.82 & 155 & 0.088 & 0.95 & 2.88 & 156 & 0.088 & 1.25 & 2.13 & 0.65 & 0 \\
\hline 0.592 & 2.49 & 150 & 0.06 & 0.58 & 2.48 & 149 & 0.063 & 2.03 & 0.40 & 0.67 & 5.00 \\
\hline
\end{tabular}


In WEDM process, machining rate is a desirable response characteristic and it should be as maximum as possible to have the least machining cycle time leading to increased productivity (Saha et al., 2007). The most widely used surface quality indicator is the center line average $(\mathrm{Ra})$ value. It plays a crucial role in evaluating and measuring the quality of a machined part. The ability of a machined part to withstand stresses, temperature, friction and corrosion is greatly affected by its roughness. In addition, roughness has also an impact on other properties, like wear resistance, light reflection and coating. The difficulty in controlling surface roughness is mainly due to the intrinsic complexity of the phenomenon that generates its formation (Pontes et al., 2009). For these reasons, surface modeling has become not just an especially defying issue but an area of great interest for research. Dimensional deviation is the difference between the observed and the target dimensional values, and it is a measure of accuracy of a machining process (Kumar et al., 2013 ${ }^{b}$ ). Wire wear ratio is normally defined as the ratio of the weight loss of wire after the WEDM process to the initial wire weight. Many researchers (Prasad et al., 2014; Goswami \& Kumar, 2014) have investigated the effects of different WEDM process parameters on WWR, and have experimentally observed that increasing values of pulse duration and open circuit voltage would cause an increment in WWR, whereas, increasing wire speed and dielectric fluid pressure would decrease it. Figs. 3-6 compare the experimental and ANN predicted values of M/c rate, Ra, Dd and WWR respectively for the considered WEDM process, and it is interesting to observe that for all the four responses, the ANN predicted responses closely match with those obtained experimentally. It is also observed that the average prediction errors for M/c rate, Ra, Dd and WWR are only $3.17 \%, 2.30 \%, 1.01 \%$ and $4.35 \%$ respectively which confirm the developed ANN model to almost accurately predict the output responses for a given set of WEDM process parameters.

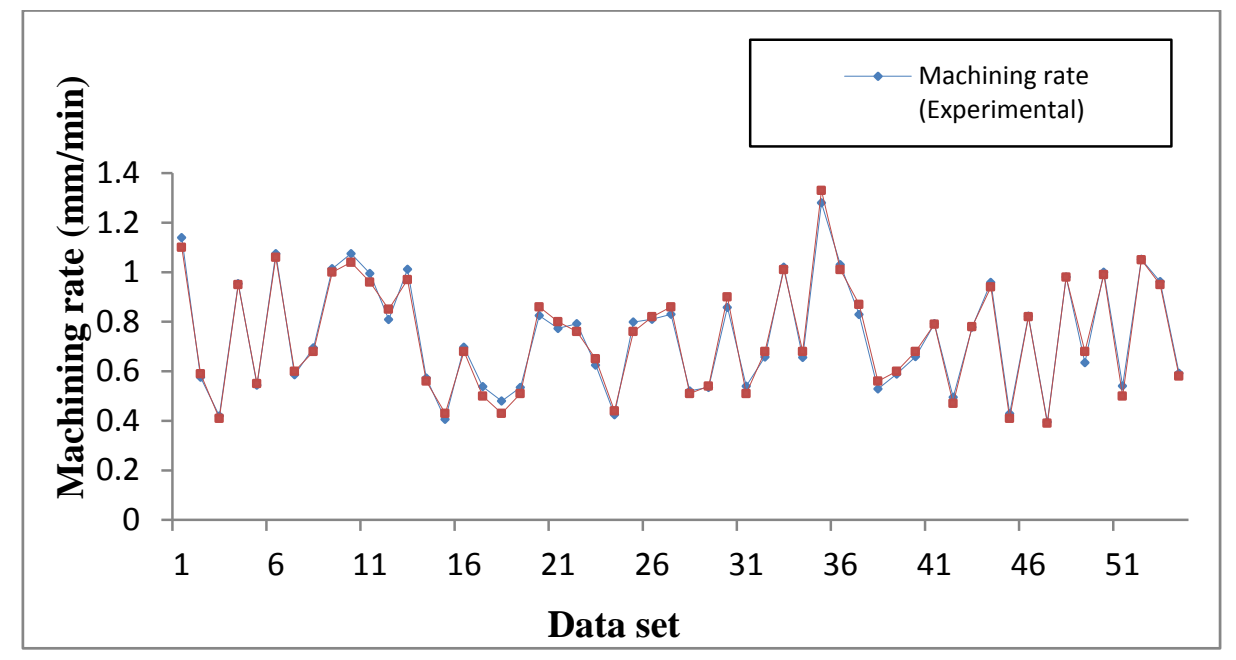

Fig. 3. Comparison of experimental and ANN predicted values for machining rate

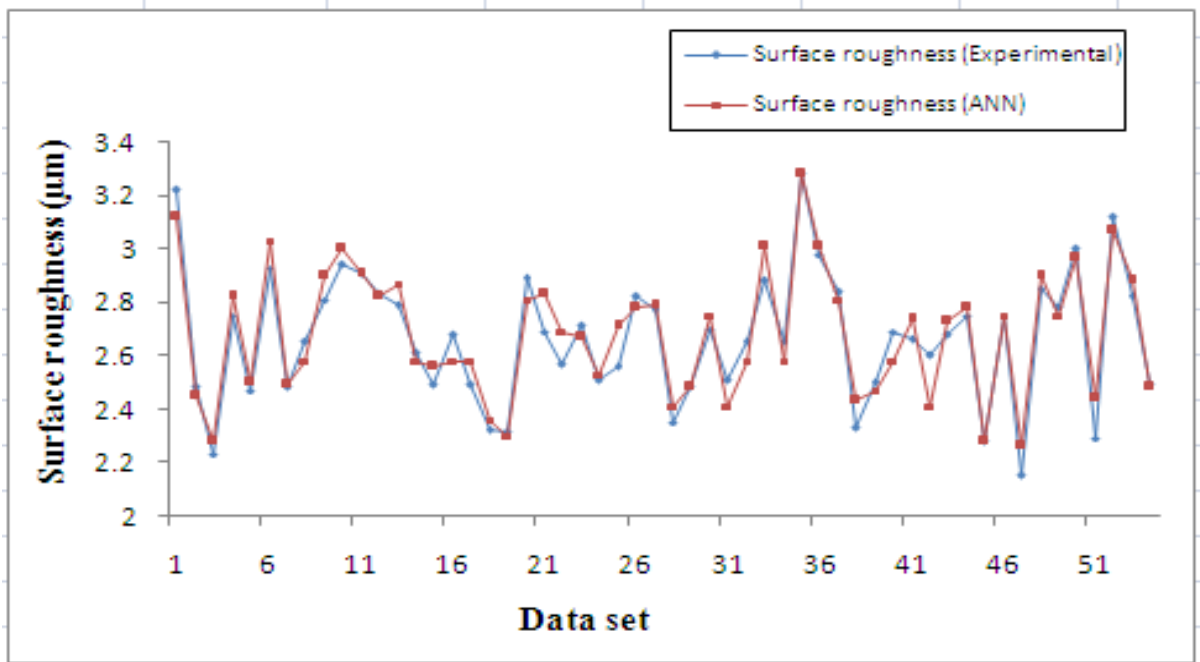

Fig. 4. Comparison of experimental and ANN predicted surface roughness values 


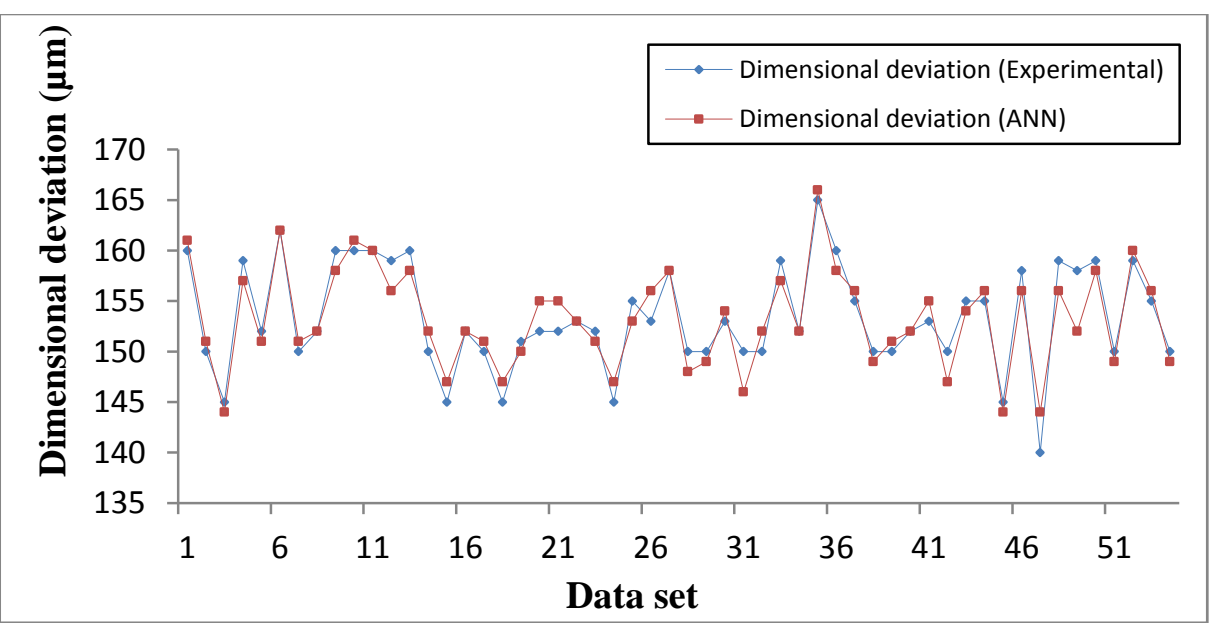

Fig. 5. Comparison of experimental and ANN predicted dimensional deviations

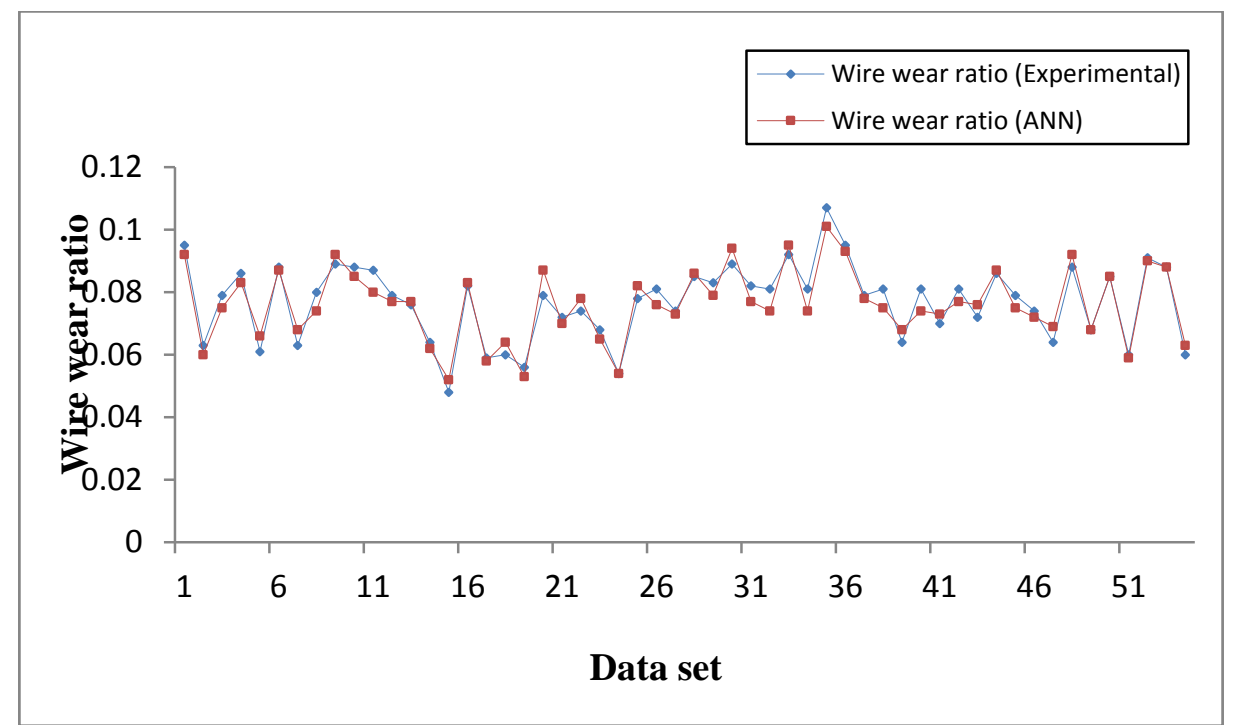

Fig. 6. Comparison of experimental and ANN predicted wire wear ratio values

An ANN model is also developed for reverse mapping of the considered WEDM process based on a 45-6 ANN architecture. This model for reverse mapping is also trained using the simulated data and is subsequently used for prediction of the tentative settings of the WEDM process parameters based on a set of desired response characteristics. It can also be treated as an advisory system which in absence of human experts, can predict the settings of various process parameters in a WEDM set-up in order to achieve the desired responses according to the requirements of the end users. Table 3 provides a set of 40 simulated data as used for training of the developed ANN for reverse mapping. The predicted values of various WEDM process parameters for the given set of responses are shown in Table 4. From this table, it is observed that the average prediction errors for the six WEDM process parameters, i.e. $\mathrm{T}_{\text {on, }}$

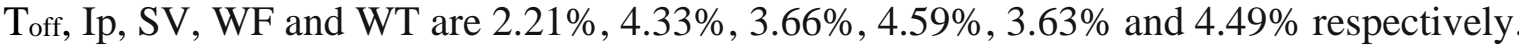

Figs. 7-12 respectively compare the simulated and ANN predicted values of all the six WEDM process parameters. This reverse model is now specifically applied for a single input dataset which can be thought of as the requirement of the end user, and it successfully predicts the necessary WEDM process parameter settings to achieve those desired response values. For the response values of M/c rate $=1.5$ $\mathrm{mm} / \mathrm{min}, \mathrm{Ra}=2.00 \mu \mathrm{m}, \mathrm{Dd}=150 \mu \mathrm{m}$ and $\mathrm{WWR}=0.1$, the corresponding WEDM process parameters are to be set at $\mathrm{T}_{\mathrm{on}}=116 \mu \mathrm{s}, \mathrm{T}_{\text {off }}=53 \mu \mathrm{s}, \mathrm{Ip}=174 \mathrm{~A}, \mathrm{SV}=37 \mathrm{~V}, \mathrm{WF}=2 \mathrm{~m} / \mathrm{min}$ and $\mathrm{WT}=876 \mathrm{~g}$. For the considered WEDM process, it is thus recommended to set the neighborhood process settings at $\mathrm{T}_{\text {on }}$ $=116 \mu \mathrm{s}, \mathrm{T}_{\text {off }}=50 / 56 \mu \mathrm{s}, \mathrm{Ip}=160 \mathrm{~A}, \mathrm{SV}=40 \mathrm{~V}, \mathrm{WF}=4 \mathrm{~m} / \mathrm{min}$ and WT $=950 \mathrm{~g}$ in order to achieve the desired responses. 
The pulse on time represents the duration of machining time in micro seconds during which the current is flowing in each cycle. During this time, the voltage is applied across the electrodes. The single pulse discharge energy increases with increasing pulse on time, resulting in higher machining rate. With higher values of pulse on time, however, surface roughness tends to be higher. The higher value of discharge energy may also cause wire breakage.

Table 3

Simulated data for reverse mapping

\begin{tabular}{|c|c|c|c|c|c|c|c|c|c|c|}
\hline Exp. No. & $\mathrm{T}_{\text {on }}$ & $T_{\text {off }}$ & Ip & SV & WF & WT & $\mathrm{M} / \mathrm{c}$ rate & $\mathrm{Ra}$ & $\mathrm{Dd}$ & WWR \\
\hline 1 & 120 & 56 & 160 & 60 & 7 & 950 & 0.792 & 2.66 & 153 & 0.07 \\
\hline 2 & 112 & 44 & 160 & 60 & 7 & 950 & 0.495 & 2.6 & 150 & 0.081 \\
\hline 3 & 116 & 50 & 200 & 60 & 7 & 1400 & 0.778 & 2.68 & 155 & 0.072 \\
\hline 4 & 116 & 44 & 120 & 50 & 4 & 950 & 0.959 & 2.75 & 155 & 0.086 \\
\hline 5 & 112 & 50 & 160 & 60 & 10 & 950 & 0.559 & 3.03 & 149 & 0.099 \\
\hline 6 & 120 & 50 & 200 & 50 & 7 & 500 & 0.684 & 2.30 & 153 & 0.082 \\
\hline 7 & 116 & 56 & 160 & 50 & 4 & 500 & 0.925 & 2.92 & 146 & 0.089 \\
\hline 8 & 112 & 50 & 160 & 60 & 4 & 950 & 0.653 & 2.26 & 154 & 0.068 \\
\hline 9 & 116 & 44 & 120 & 50 & 10 & 950 & 1.123 & 2.70 & 158 & 0.076 \\
\hline 10 & 116 & 50 & 120 & 60 & 7 & 500 & 0.679 & 2.41 & 145 & 0.093 \\
\hline 11 & 120 & 50 & 160 & 40 & 4 & 950 & 0.763 & 2.99 & 161 & 0.088 \\
\hline 12 & 116 & 56 & 160 & 50 & 10 & 1400 & 0.693 & 2.47 & 148 & 0.100 \\
\hline 13 & 116 & 50 & 160 & 50 & 7 & 950 & 1.056 & 2.76 & 162 & 0.074 \\
\hline 14 & 116 & 44 & 160 & 50 & 4 & 500 & 0.549 & 3.17 & 149 & 0.064 \\
\hline 15 & 120 & 50 & 160 & 40 & 10 & 950 & 1.136 & 3.11 & 160 & 0.100 \\
\hline 16 & 120 & 56 & 160 & 40 & 7 & 950 & 0.712 & 3.01 & 156 & 0.084 \\
\hline 17 & 120 & 50 & 160 & 60 & 4 & 950 & 0.708 & 2.41 & 159 & 0.071 \\
\hline 18 & 116 & 44 & 160 & 50 & 10 & 500 & 0.805 & 2.72 & 149 & 0.053 \\
\hline 19 & 116 & 50 & 160 & 50 & 7 & 950 & 1.064 & 3.05 & 152 & 0.073 \\
\hline 20 & 112 & 50 & 120 & 50 & 7 & 500 & 0.446 & 2.72 & 161 & 0.054 \\
\hline 21 & 116 & 50 & 160 & 50 & 7 & 950 & 1.007 & 2.89 & 152 & 0.099 \\
\hline 22 & 116 & 50 & 120 & 60 & 7 & 1400 & 0.530 & 2.86 & 150 & 0.055 \\
\hline 23 & 112 & 56 & 160 & 40 & 7 & 950 & 0.884 & 3.06 & 147 & 0.088 \\
\hline 24 & 116 & 56 & 120 & 50 & 10 & 950 & 1.057 & 3.00 & 146 & 0.074 \\
\hline 25 & 116 & 50 & 200 & 40 & 7 & 1400 & 0.509 & 2.96 & 147 & 0.078 \\
\hline 26 & 116 & 50 & 200 & 60 & 7 & 500 & 1.016 & 2.65 & 156 & 0.065 \\
\hline 27 & 116 & 56 & 200 & 50 & 10 & 950 & 0.551 & 3.27 & 146 & 0.094 \\
\hline 28 & 116 & 50 & 120 & 40 & 7 & 1400 & 1.053 & 3.18 & 161 & 0.054 \\
\hline 29 & 112 & 50 & 120 & 50 & 7 & 1400 & 1.076 & 3.09 & 155 & 0.052 \\
\hline 30 & 116 & 56 & 200 & 50 & 4 & 950 & 0.793 & 3.00 & 145 & 0.105 \\
\hline 31 & 120 & 50 & 160 & 60 & 10 & 950 & 0.866 & 3.16 & 146 & 0.097 \\
\hline 32 & 120 & 50 & 120 & 50 & 7 & 500 & 1.135 & 2.65 & 152 & 0.104 \\
\hline 33 & 112 & 50 & 160 & 40 & 10 & 950 & 0.612 & 2.49 & 146 & 0.049 \\
\hline 34 & 112 & 50 & 200 & 50 & 7 & 500 & 1.036 & 2.60 & 157 & 0.069 \\
\hline 35 & 112 & 44 & 160 & 40 & 7 & 950 & 0.678 & 2.83 & 150 & 0.057 \\
\hline 36 & 112 & 50 & 200 & 50 & 7 & 1400 & 1.069 & 2.80 & 151 & 0.065 \\
\hline 37 & 116 & 50 & 160 & 50 & 7 & 950 & 1.000 & 2.95 & 158 & 0.051 \\
\hline 38 & 116 & 44 & 200 & 50 & 4 & 950 & 0.786 & 2.78 & 148 & 0.065 \\
\hline 39 & 116 & 50 & 160 & 50 & 7 & 950 & 0.938 & 3.24 & 151 & 0.058 \\
\hline 40 & 120 & 50 & 200 & 60 & 4 & 500 & 0.443 & 3.02 & 152 & 0.054 \\
\hline
\end{tabular}

The pulse off time represents the duration of time in micro seconds between two simultaneous sparks. The voltage is absent during this part of the cycle. With a lower value of pulse off time, there are more number of discharges in a given time, resulting in increase in sparking efficiency. As a result, the machining rate also increases. Using very low values of pulse off time, however, may cause wire breakage which in turn reduces the machining efficiency. As and when the discharge conditions become unstable, the pulse off time can be increased. This will allow lower pulse duty factor and will reduce the average gap current. From Fig. 7 and Fig. 8, it is observed that the predicted values of pulse on and pulse off times match well with the simulated dataset values. There are some small deviations between the simulated and predicted values which can be minimized further using more accurate training data. 
The peak current is the maximum value of the current passing through the electrodes for a given pulse. An increase in peak current will increase the pulse discharge energy which in turn can improve the machining rate further. For higher values of peak current, gap conditions may become unstable with improper combination of other process parameter settings. Wire feed is the rate at which the wire electrode travels along the wire guide path and is fed continuously for sparking. It is always desirable to set the wire feed to be maximum. This will result in less wire breakage, better machining stability and slightly more cutting speed. Both the process parameters, i.e. peak current and wire feed are considered to be critical in WEDM process.

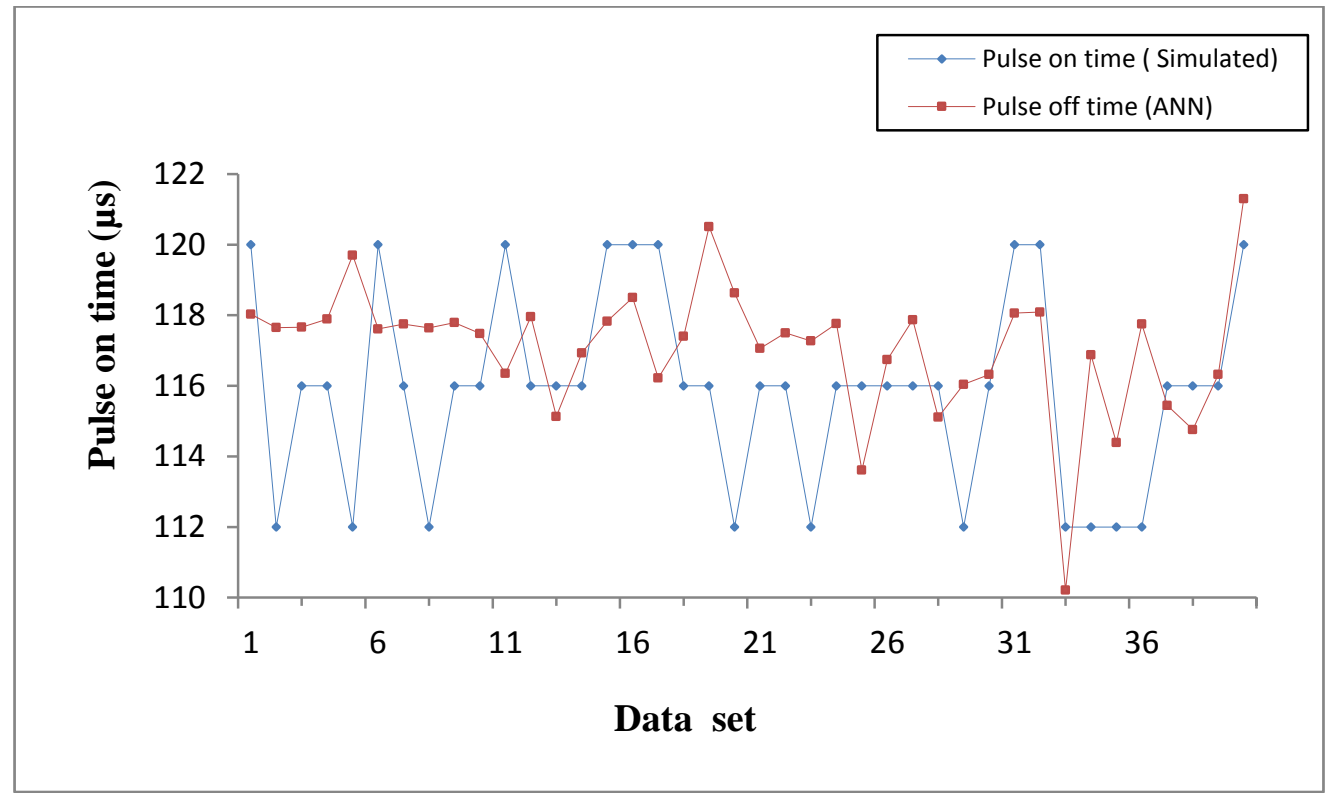

Fig. 7 Comparison of simulated and ANN predicted pulse on time values

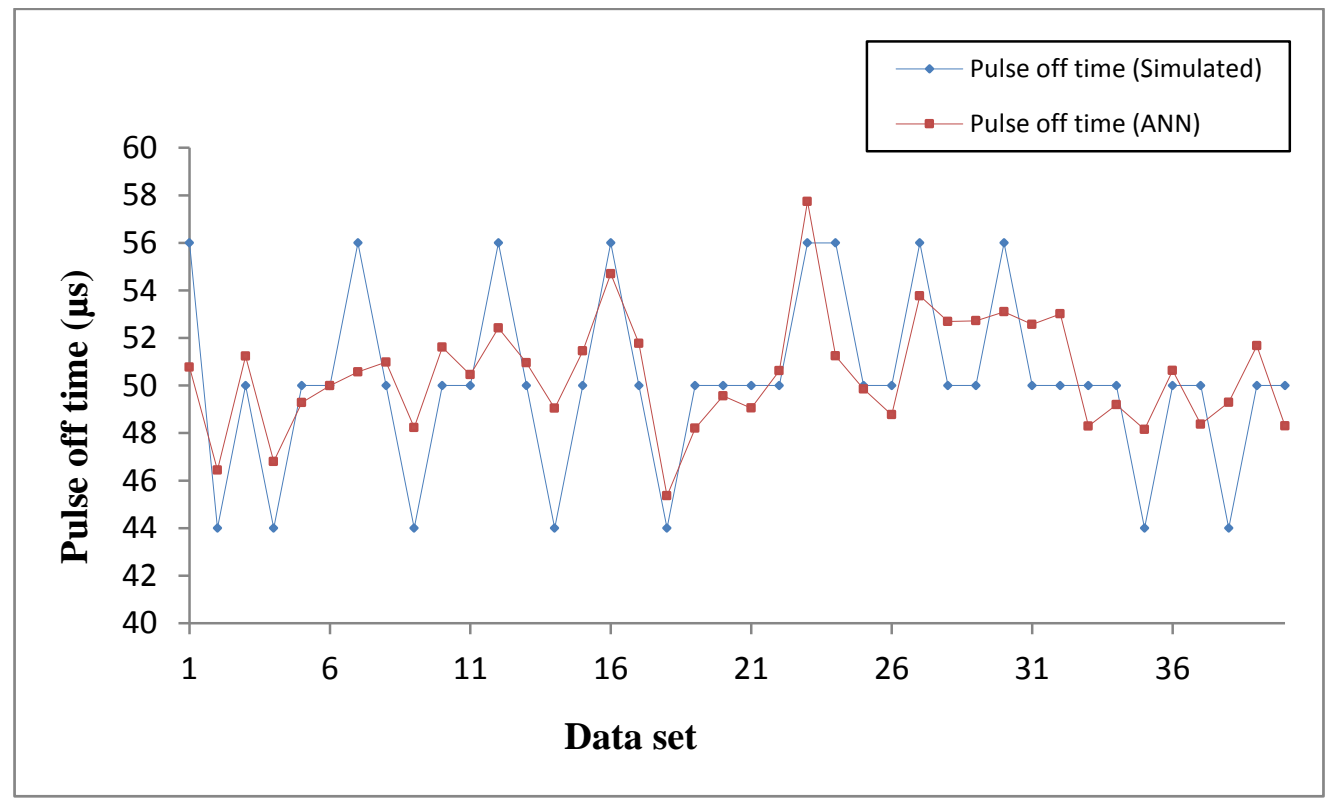

Fig. 8 Comparison of simulated and ANN predicted pulse off time values

It can be confirmed from Fig. 9 and Fig. 10 that the developed reverse ANN model is quite successful in predicting both these process parameters. The spark gap voltage is a reference voltage for the actual gap between the workpiece and the wire used for the machining operation. On the other hand, wire tension determines how much the wire needs to be stretched between the upper and lower wire guides. This is a gram equivalent load with which the continuously fed wire is kept under tension so that it remains straight between the wire guides. More the thickness of the workpiece, more is the wire tension 
required. Improper setting of tension may result in job inaccuracies as well as wire breakage. The developed reverse ANN model is also capable to successfully predict the spark gap voltage and wire tension which can be validated from Fig. 11 and Fig. 12.

Table 4

ANN predicted results in reverse mapping

\begin{tabular}{|c|c|c|c|c|c|c|c|c|c|c|c|c|c|c|c|}
\hline \multicolumn{4}{|c|}{ Input responses } & \multicolumn{6}{|c|}{ ANN predicted process parameters } & \multicolumn{6}{|c|}{ Prediction error (\%) } \\
\hline $\mathrm{M} / \mathrm{c}$ rate & $\mathrm{Ra}$ & Dd & WWR & $\mathrm{T}_{\mathrm{on}}$ & $\mathrm{T}_{\text {off }}$ & Ip & SV & WF & WT & $\mathrm{T}_{\text {on }}$ & $\mathrm{T}_{\text {off }}$ & Ip & SV & WF & WT \\
\hline 0.792 & 2.66 & 153 & 0.07 & 118.03 & 50.77 & 165.29 & 61.22 & 7.76 & 934.76 & 1.64 & 9.34 & 3.31 & 2.03 & 10.86 & 1.60 \\
\hline 0.495 & 2.6 & 150 & 0.081 & 117.65 & 46.44 & 162.94 & 60.03 & 7.69 & 1008.34 & 5.04 & 5.55 & 1.84 & 0.05 & 9.86 & 6.14 \\
\hline 0.778 & 2.68 & 155 & 0.072 & 117.66 & 51.23 & 200.15 & 58.89 & 7.21 & 1395.66 & 1.43 & 2.46 & 0.08 & 1.85 & 3.00 & 0.31 \\
\hline 0.959 & 2.75 & 155 & 0.086 & 117.89 & 46.80 & 120.29 & 49.37 & 4.24 & 947.85 & 1.63 & 6.36 & 0.24 & 1.26 & 6.00 & 0.23 \\
\hline 0.559 & 3.03 & 149 & 0.099 & 119.70 & 49.28 & 160.69 & 56.83 & 9.72 & 946.65 & 6.88 & 1.44 & 0.43 & 5.28 & 2.80 & 0.35 \\
\hline 0.684 & 2.30 & 153 & 0.082 & 117.61 & 49.99 & 196.36 & 50.48 & 6.87 & 468.10 & 1.99 & 0.02 & 1.82 & 0.96 & 1.86 & 6.38 \\
\hline 0.925 & 2.92 & 146 & 0.089 & 117.75 & 50.57 & 158.29 & 53.18 & 3.62 & 458.44 & 1.51 & 9.70 & 1.07 & 6.36 & 9.50 & 8.31 \\
\hline 0.653 & 2.26 & 154 & 0.068 & 117.64 & 50.98 & 150.31 & 61.23 & 4.09 & 892.30 & 5.04 & 1.96 & 6.06 & 2.05 & 2.25 & 6.07 \\
\hline 1.123 & 2.70 & 158 & 0.076 & 117.79 & 48.23 & 122.17 & 50.83 & 9.29 & 967.82 & 1.54 & 9.61 & 1.81 & 1.66 & 7.10 & 1.88 \\
\hline 0.679 & 2.41 & 145 & 0.093 & 117.48 & 51.61 & 118.36 & 58.55 & 7.09 & 463.44 & 1.28 & 3.22 & 1.37 & 2.42 & 1.29 & 7.31 \\
\hline 0.763 & 2.99 & 161 & 0.088 & 116.35 & 50.45 & 166.54 & 42.17 & 3.88 & 852.47 & 3.04 & 0.90 & 4.09 & 5.43 & 3.00 & 10.27 \\
\hline 0.693 & 2.47 & 148 & 0.100 & 117.96 & 52.42 & 172.92 & 50.90 & 9.25 & 1398.10 & 1.69 & 6.39 & 8.07 & 1.80 & 7.50 & 0.14 \\
\hline 1.056 & 2.76 & 162 & 0.074 & 115.13 & 50.95 & 154.58 & 50.23 & 7.05 & 878.77 & 0.75 & 1.90 & 3.39 & 0.46 & 0.71 & 7.50 \\
\hline 0.549 & 3.17 & 149 & 0.064 & 116.93 & 49.04 & 166.82 & 51.43 & 3.96 & 487.17 & 0.80 & 11.45 & 4.26 & 2.86 & 1.00 & 2.57 \\
\hline 1.136 & 3.11 & 160 & 0.100 & 117.83 & 51.45 & 158.25 & 42.56 & 9.11 & 856.32 & 1.81 & 2.90 & 1.09 & 6.40 & 8.90 & 9.86 \\
\hline 0.712 & 3.01 & 156 & 0.084 & 118.50 & 54.70 & 177.88 & 40.72 & 7.69 & 846.03 & 1.25 & 2.32 & 11.18 & 1.80 & 9.86 & 10.94 \\
\hline 0.708 & 2.41 & 159 & 0.071 & 116.22 & 51.77 & 145.96 & 58.95 & 4.09 & 898.29 & 3.15 & 3.54 & 8.78 & 1.75 & 2.25 & 5.44 \\
\hline 0.805 & 2.72 & 149 & 0.053 & 117.40 & 45.36 & 147.91 & 52.64 & 9.73 & 472.22 & 1.21 & 3.09 & 7.56 & 5.28 & 2.70 & 5.56 \\
\hline 1.064 & 3.05 & 152 & 0.073 & 120.51 & 48.20 & 162.23 & 46.27 & 7.20 & 891.33 & 3.89 & 3.60 & 1.39 & 7.46 & 2.86 & 6.18 \\
\hline 0.446 & 2.72 & 161 & 0.054 & 118.63 & 49.56 & 119.48 & 55.80 & 7.44 & 515.51 & 5.92 & 0.88 & 0.43 & 11.60 & 6.29 & 3.10 \\
\hline 1.007 & 2.89 & 152 & 0.099 & 117.06 & 49.05 & 167.54 & 51.53 & 6.92 & 996.11 & 0.91 & 1.90 & 4.71 & 3.06 & 1.14 & 4.85 \\
\hline 0.530 & 2.86 & 150 & 0.055 & 117.50 & 50.62 & 120.14 & 60.40 & 7.03 & 1355.23 & 1.29 & 1.24 & 0.12 & 0.67 & 0.43 & 3.20 \\
\hline 0.884 & 3.06 & 147 & 0.088 & 117.27 & 57.74 & 157.46 & 40.51 & 7.57 & 945.95 & 4.71 & 3.11 & 1.59 & 1.28 & 8.14 & 0.43 \\
\hline 1.057 & 3.00 & 146 & 0.074 & 117.76 & 51.24 & 120.98 & 48.58 & 9.91 & 1000.08 & 1.52 & 8.50 & 0.82 & 2.84 & 0.90 & 5.27 \\
\hline 0.509 & 2.96 & 147 & 0.078 & 113.61 & 49.85 & 209.69 & 42.13 & 6.93 & 1252.06 & 2.06 & 0.30 & 4.85 & 5.33 & 1.00 & 10.57 \\
\hline 1.016 & 2.65 & 156 & 0.065 & 116.74 & 48.77 & 200.62 & 57.97 & 7.58 & 498.78 & 0.64 & 2.46 & 0.31 & 3.38 & 8.29 & 0.24 \\
\hline 0.551 & 3.27 & 146 & 0.094 & 117.87 & 53.77 & 202.27 & 53.96 & 9.45 & 881.49 & 1.61 & 3.98 & 1.14 & 7.92 & 5.50 & 7.21 \\
\hline 1.053 & 3.18 & 161 & 0.054 & 115.11 & 52.69 & 119.42 & 42.53 & 6.93 & 1405.41 & 0.77 & 5.38 & 0.48 & 6.33 & 1.00 & 0.39 \\
\hline 1.076 & 3.09 & 155 & 0.052 & 116.04 & 52.72 & 133.62 & 47.57 & 7.03 & 1363.97 & 3.61 & 5.44 & 11.35 & 4.86 & 0.43 & 2.57 \\
\hline 0.793 & 3.00 & 145 & 0.105 & 116.32 & 53.10 & 206.32 & 50.87 & 3.83 & 914.36 & 0.28 & 5.18 & 3.16 & 1.74 & 4.25 & 3.75 \\
\hline 0.866 & 3.16 & 146 & 0.097 & 118.06 & 52.57 & 169.70 & 61.38 & 9.65 & 952.88 & 1.62 & 5.14 & 6.06 & 2.30 & 3.50 & 0.30 \\
\hline 1.135 & 2.65 & 152 & 0.104 & 118.09 & 53.01 & 122.30 & 52.97 & 7.67 & 477.80 & 1.59 & 6.02 & 1.92 & 5.94 & 9.57 & 4.44 \\
\hline 0.612 & 2.49 & 146 & 0.049 & 110.21 & 48.29 & 165.78 & 42.66 & 9.58 & 923.14 & 1.60 & 3.42 & 3.61 & 6.65 & 4.20 & 2.83 \\
\hline 1.036 & 2.60 & 157 & 0.069 & 116.88 & 49.19 & 182.71 & 48.60 & 7.55 & 552.46 & 4.36 & 1.62 & 8.65 & 2.80 & 7.86 & 10.49 \\
\hline 0.678 & 2.83 & 150 & 0.057 & 114.39 & 48.15 & 171.19 & 41.40 & 6.73 & 989.42 & 2.13 & 9.43 & 6.99 & 3.50 & 3.86 & 4.15 \\
\hline 1.069 & 2.80 & 151 & 0.065 & 117.75 & 50.63 & 202.64 & 48.75 & 7.03 & 1356.08 & 5.13 & 1.26 & 1.32 & 2.50 & 0.43 & 3.14 \\
\hline 1.000 & 2.95 & 158 & 0.051 & 115.44 & 48.37 & 162.28 & 50.45 & 6.83 & 946.13 & 0.48 & 3.26 & 1.43 & 0.90 & 2.43 & 0.41 \\
\hline 0.786 & 2.78 & 148 & 0.065 & 114.76 & 49.29 & 183.68 & 52.03 & 3.60 & 1000.23 & 1.07 & 12.02 & 8.16 & 4.06 & 10.00 & 5.29 \\
\hline 0.938 & 3.24 & 151 & 0.058 & 116.32 & 51.67 & 146.90 & 46.56 & 7.58 & 856.13 & 0.28 & 3.34 & 8.19 & 6.88 & 8.29 & 9.88 \\
\hline 0.443 & 3.02 & 152 & 0.054 & 121.30 & 48.30 & 193.70 & 57.80 & 4.10 & 498.50 & 1.08 & 3.40 & 3.15 & 3.67 & 2.50 & 0.30 \\
\hline
\end{tabular}

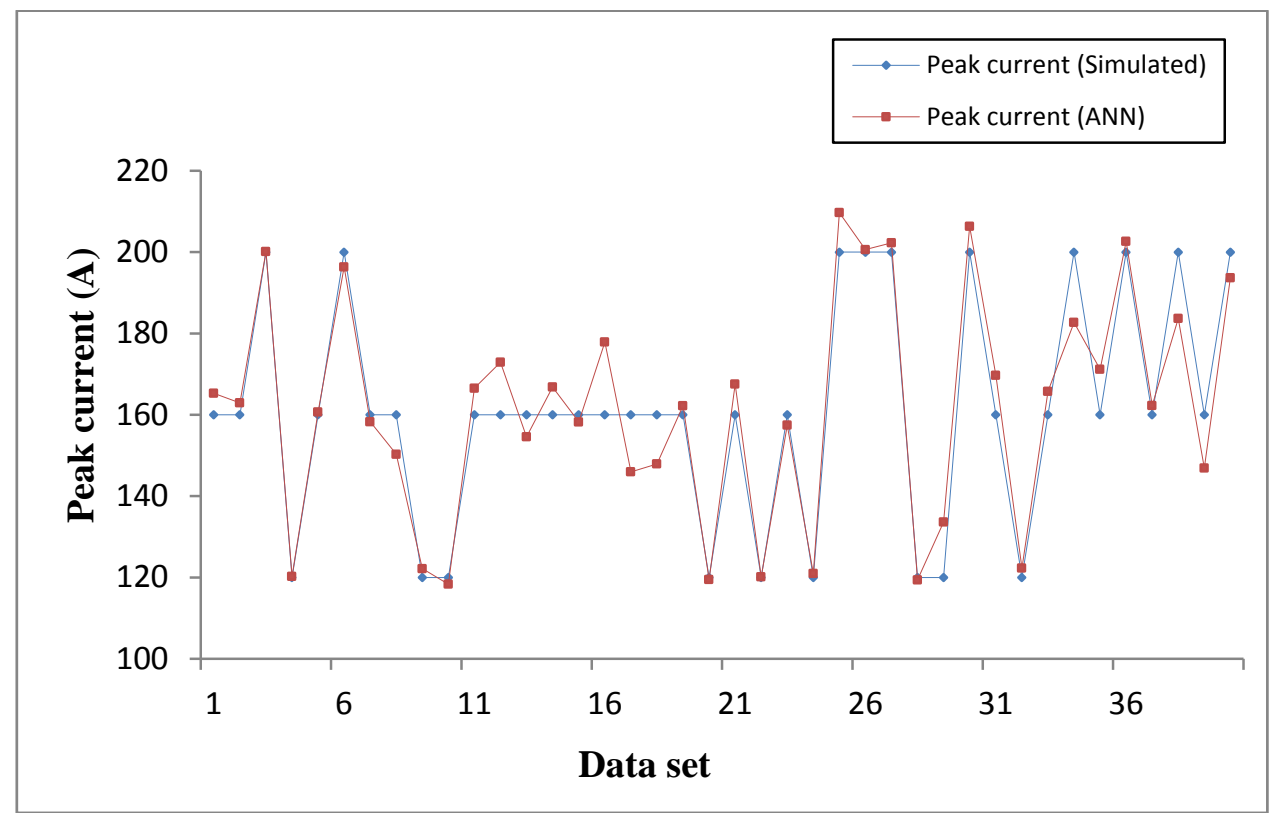

Fig. 9. Comparison of simulated and ANN predicted peak current values 


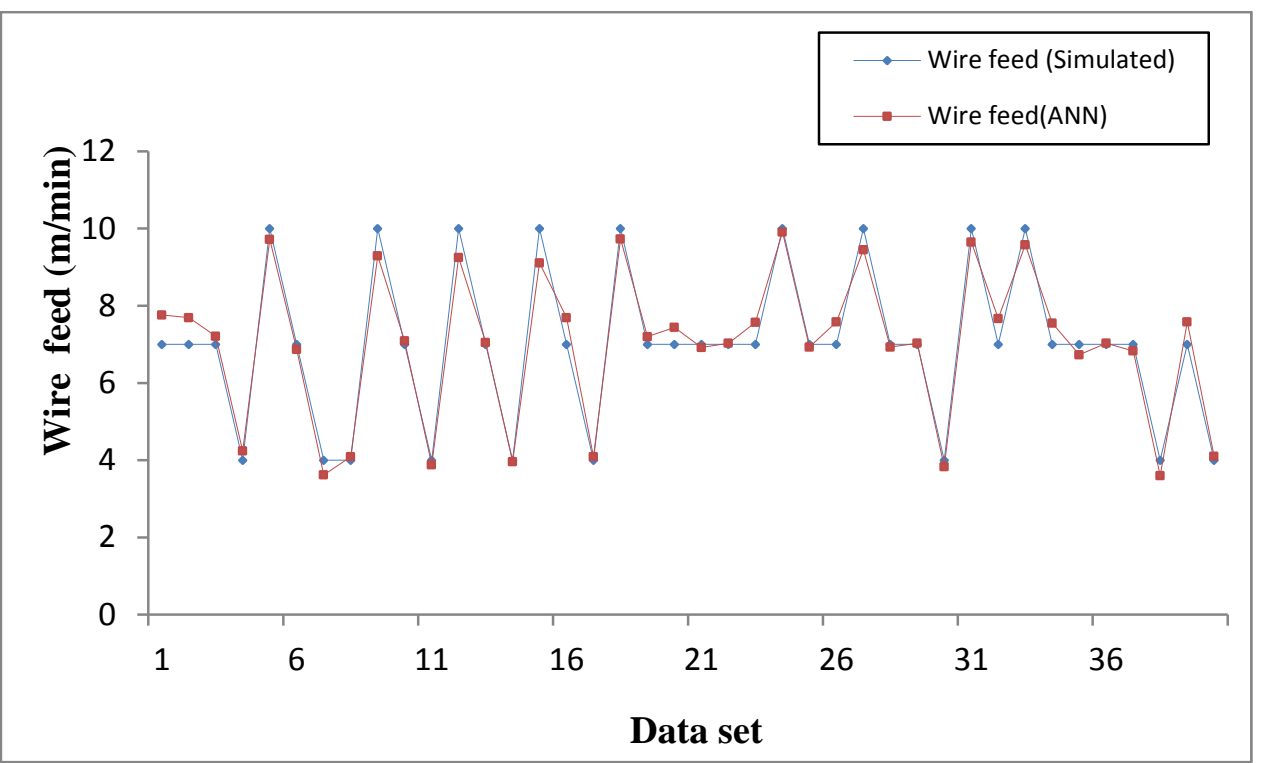

Fig. 10. Comparison of simulated and ANN predicted wire feed values

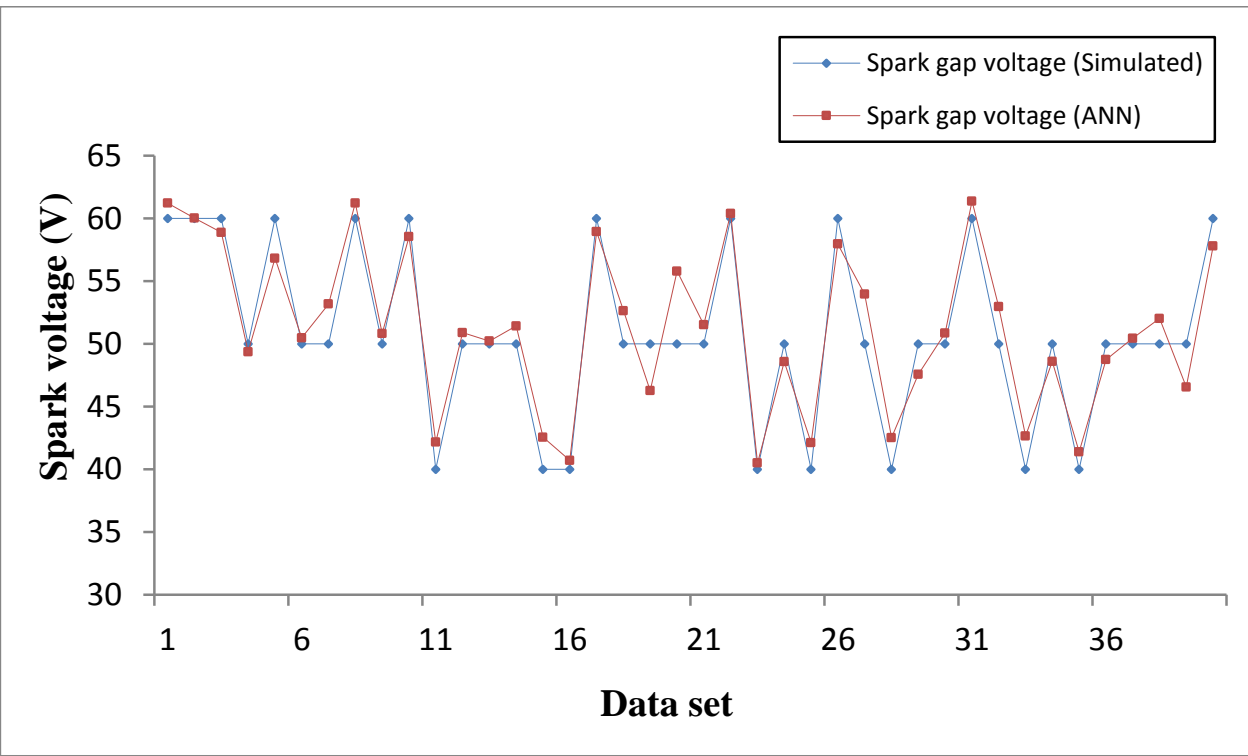

Fig. 11. Comparison of simulated and ANN predicted spark voltages

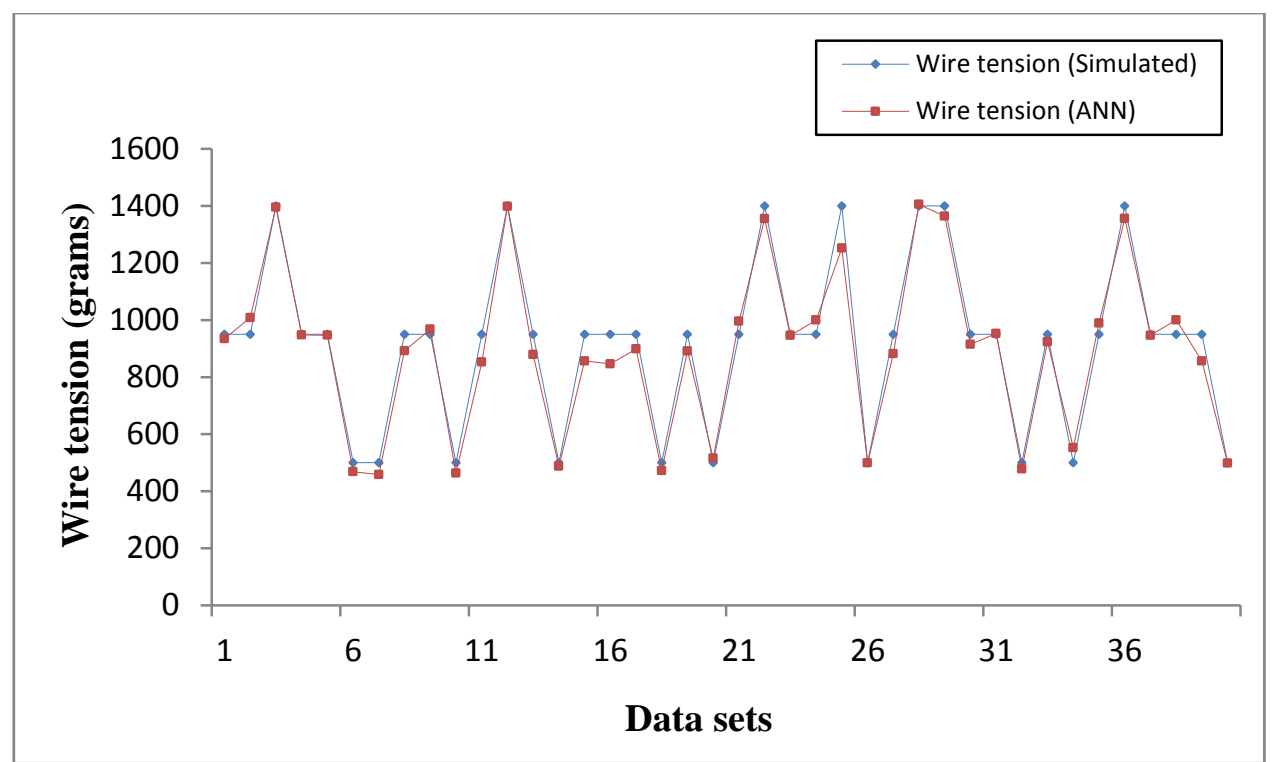

Fig. 12. Comparison of simulated and ANN predicted wire tension values 


\section{Conclusions}

In this paper, a data mining approach employing artificial neural networks has been applied to a wire electrical discharge machining process for prediction of its four responses based on six process parameters, i.e. pulse on time, pulse off time, peak current, wire feed, wire tension and servo voltage through forward mapping. Using a reverse mapping approach, based on the end user's requirements for the desired values of various responses, the optimal settings of WEDM process parameters were also predicted. It has been observed that the ANN predicted results closely corroborate with the experimental and simulated results which prove the capability of artificial neural networks as an effective tool for developing such prediction models to cater the needs of both the operators and the end users. It can also be extended further for modeling other complex machining processes with a large number of control parameters and responses.

\section{References}

Chandrashekarappa, M.P.G., Krishna, P., \& Parappagoudar, B. (2014). Forward and reverse process models for the squeeze casting process using neural network based approaches. Applied Computational Intelligence and Soft Computing. Article ID 293976, 12 pages, http://dx.doi.org/10.1155/2014/293976.

Ghodsisyeh, D., Golshan, A., \& Shirvanehdeh, J.A. (2013). Review on current research trends in wire electrical discharge machining (WEDM). Indian Journal of Science and Technology, 6(2), 154-168.

Goswami, A., \& Kumar, J. (2014). Investigation of surface integrity, material removal rate and wire wear ratio for WEDM of Nimonic 80A alloy using GRA and Taguchi method. Engineering Science and Technology, an International Journal, 17, 173-184.

Ho, K.H., Newman, S.T., Rahimifard, S., \& Allen, R.D. (2004). State of the art in wire electrical discharge machining (WEDM). International Journal of Machine Tools \& Manufacture, 44(12-13), 1247-1259.

Kumar, A., Kumar, V., \& Kumar, J. (2013 $)$. Multi-response optimization of process parameters based on response surface methodology for pure titanium using WEDM process. International Journal of Advanced Manufacturing Technology, 68(9-12), 2645- 2668.

Kumar, A., Kumar, V., \& Kumar, J. (2013 $)$. Effect of machining parameters on dimensional deviation in wire electro discharge machining process using pure titanium. Journal of Engineering and Technology, 3(2), 105-112.

Mukherjee, R., Chakraborty, S., \& Samanta, S. (2012). Selection of wire electrical discharge machining process parameters using non-traditional optimization algorithms. Applied Soft Computing, 12(8), 2506-2516.

Pontes, F.J., Ferreira, J.R., Silva, M.B., Paiva, A.P., \& Balestrassi, P.P. (2009). Artificial neural networks for machining process surface roughness modeling. International Journal of Advanced Manufacturing Technology, 49(9-12), 879-902.

Prasad, D.V.S.S.S.V., \& Gopala Krishna, A. (2014). Empirical modeling and optimization of kerf and wire wear ratio in wire electrical discharge machining. International Journal of Advanced Manufacturing Technology, 77(1-4), 427-441.

Saha, P., Singha, A., Pal, S.K., \& Saha, P. (2007). Soft computing models based prediction of cutting speed and surface roughness in wire electro discharge machining of tungsten carbide cobalt composite. International Journal of Advanced Manufacturing Technology, 49(1-2), 74-84.

Saha, P., Tarafdar, D., Pal, S.K., Saha, P., Srivastava, A.K., \& Das, K. (2008). Modelling of wire electro-discharge machining of TiC/Fe in situ metal matrix using normalized RGFN with enhanced $k$-means clustering technique. International Journal of Advanced Manufacturing Technology, 43(1-2), 107-116.

Samarasinghe, S. (2006). Neural Networks for Applied Sciences and Engineering: From Fundamentals to Complex Pattern Recognition. New York: Auerbach Publications.

Scott, D., Boyina, S., \& Rajurkar, K.P. (1991). Analysis and optimization of parameter combinations in wire electrical discharge machining. International Journal of Production Research, 29(11), 2189-2207.

Shandilya, P., Jain, P.K., \& Jain, N.K. (2013). RSM and ANN modeling approaches for predicting average cutting speed during WEDM of SiCp/6061 Al MMC. Procedia Engineering, 64, 767-774.

Sivanandam, P. (2003). Introduction to Artificial Neural Networks, New Delhi: Vikas Publishing House.

Spedding, T.A., \& Wang, Z.Q. $\left(1997^{\mathrm{a}}\right)$. Parametric optimization and surface characterization of wire electrical discharge machining process. Precision Engineering, 20(1), 5-15.

Spedding, T.A., \& Wang, Z.Q. (1997b). Study on modeling of wire EDM process. Journal of Materials Processing Technology, 69(1-3), 18-28.

Ugrasen, G., Ravindra, H.V., Prakash, G.V.N., \& Keshavamurthy, K. (2014). Process optimization and estimation of machining performances using artificial neural network in wire EDM. Procedia Materials Science, 6, 1752-1760. 